\title{
An Approach for Appraising the Accuracy of Suspended-sediment Data
}

U.S. GEOLOGICAL SURVEY PROFESSIONAL PAPER 1333 


\section{An Approach for Appraising the Accuracy of Suspended-sediment Data}

By D. E. BURKHAM

U.S. GEOLOGICAL SURVEY PROFESSIONAL PAPER 1333

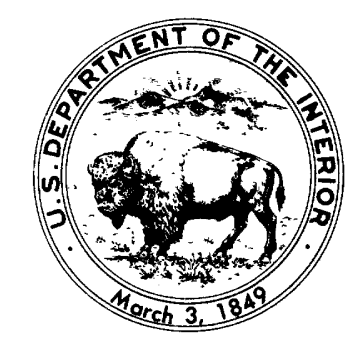




\section{DEPARTMENT OF THE INTERIOR \\ DONALD PAUL HODEL, Secretary}

\section{U.S. GEOLOGICAL SURVEY}

Dallas L. Peck, Director

First printing 1985

Second printing 1987

For sale by the Books and Open-File Reports Section, U.S. Geological Survey,

Federal Center, Box 25425, Denver, CO 80225 


\section{CONTENTS}

\begin{tabular}{|c|c|c|c|}
\hline & Page & & Page \\
\hline Abstract .... & 1 & Spatial error-Continued & \\
\hline Introduction & 1 & Application of method . & 11 \\
\hline Problem $\ldots \ldots \ldots$ & 1 & 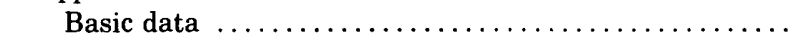 & 11 \\
\hline Purpose and scope & 2 & Standard spatial error for multivertical procedure $\ldots .$. & 11 \\
\hline Sampling error ............ & 2 & Standard spatial error for single-vertical procedure .... & 13 \\
\hline Discussion of error ........ & 2 & 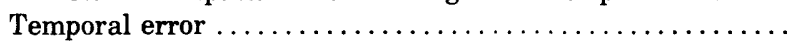 & 13 \\
\hline Approach to solution. & 3 & 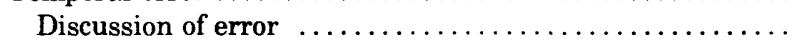 & 13 \\
\hline Application of method & 4 & Approach to solution $\ldots \ldots \ldots \ldots \ldots \ldots \ldots \ldots \ldots \ldots \ldots$ & 14 \\
\hline Basic data ............ & 4 & Application of method & 14 \\
\hline Standard sampling error . & 4 & Basic data $\ldots \ldots \ldots \ldots \ldots$ & 14 \\
\hline Spatial error $\ldots \ldots \ldots \ldots \ldots$ & 5 & Analysis of data ........... & 15 \\
\hline Discussion of error & 5 & Standard temporal error. & 15 \\
\hline Introduction $\ldots \ldots \ldots$ & 5 & Sediment-discharge error ... & 15 \\
\hline Multivertical procedure .. & 9 & Discussion of error ..... & 15 \\
\hline Single-vertical procedure & 9 & Approach to solution ... & 17 \\
\hline Single-point procedure ... & 9 & Application of method . & 17 \\
\hline Approach to solution .... & 10 & Summary and conclusions & 17 \\
\hline Multivertical procedure & 10 & References cited..$\ldots \ldots \ldots$ & 18 \\
\hline Single-vertical and single- & 10 & & \\
\hline
\end{tabular}

\section{ILLUSTRATIONS}

FIGURE 1. Schema of assumed true concentration at a vertical during $T_{2}-T_{1}$, with nomenclature $\ldots \ldots \ldots \ldots \ldots \ldots \ldots$ 2-4. Graphs showing:

2. Relation between standard sampling error and percentage sand in the sampled water-sediment mixture ..

3. A, Relation between the coefficient of variation and the percentage of the sampled water-sediment mixture that is sand; B, Relation between the coefficient of variation, the standard spatial error, and the number

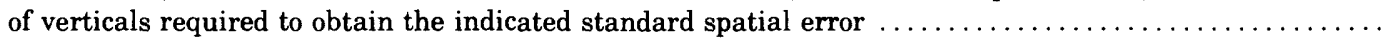

4. Relation between standard temporal error in instantaneous concentration and the average elapsed time between samples for the two indicated sites

11

11

13

13

13

14 4 5 15 17 17 7 


\section{CONVERSION FACTORS}

For readers who may prefer to use metric units rather than inch-pound units, the conversion factors for the terms used in this report are listed below.

Multiply

feet

$\mathrm{ft}^{3} / \mathrm{s}$ (cubic feet per second)

$\mathrm{mi}^{2}$ (square miles)

tons, short
By

0.3048

0.02832

2.590

0.9072
To obtain

meters

$\mathrm{m}^{3} / \mathrm{s}$ (cubic meters per second)

$\mathrm{km}^{2}$ (square kilometers)

megagrams 


\title{
AN APPROACH FOR APPRAISING THE ACCURACY OF SUSPENDED-SEDIMENT DATA
}

\author{
By D. E. BURKHAM
}

\begin{abstract}
Procedures are presented for appraising the accuracy of suspendedsediment data. The types of error involved are sampling error-error introduced in obtaining a value representing suspended-sediment concentration for a sample taken at a single vertical during the sampling time; spatial error-error in mean concentration that is determined from sampled concentration at verticals in a cross section for a point in time; temporal error-error in computed values of suspended-sediment concentration for a cross section at any point in time; and sediment-discharge error-error in computed values of suspended-sediment discharge for a cross section at any point in time. The standard error of estimate is the statistic used to represent errors.

Suspended-sediment data for 17 U.S. Geological Survey gaging stations in Arizona, California, Nebraska, New Mexico, Pennsylvania, and Washington are used in applications of the procedures. For the study sites, the magnitudes of the different types of error apparently vary directly with the percentage of the sediment-water mixture that is sand. Among the study sites, when the percentage of sand is relatively high, the magnitudes of the different types of error have a relatively wide range.

For seven sites on the Sacramento River, California, and its tributaries, the standard sampling error apparently can range from 2.5 percent for periods when the percentage of the suspended sediment that is sand is relatively low to 20 percent when the percentage sand is relatively high. For 16 sites in Arizona, California, Nebraska, New Mexico, and Pennsylvania, the coefficient of variation (ratio of standard deviation to cross-sectional mean) for concentration of suspended sediment across stream apparently can range from 2.5 percent for periods when percentage sand is relatively low to 70 percent when percentage sand is relatively high.
\end{abstract}

\section{INTRODUCTION}

\section{PROBLEM}

The U.S. Geological Survey (USGS) and other Federal, State, and local agencies obtain records of suspended-sediment discharge at many sites throughout the United States. The use of these records has greatly increased in recent years. Uses involve the evaluation of sediment transport to the oceans, geomorphological studies of denudation and rates of erosion, assessment of soil erosion and soil loss, reservoir sedimentation, general environmental impact assessment, water treatment problems of sediment-associated nutrients and pollutants, and evaluation of the precise impacts of humans. Because of the many important potential uses of suspended-sediment data, it is essential that the reliability and accuracy of the data be known. Yet the data are published without analysis of the bias or the precision of the facts presented, mainly because a direct and exact technique for appraising the accuracy of suspended-sediment data is not available.

Errors are introduced in the collection and tabulation of suspended-sediment data because, for any measurement or computational scheme, the measurement and sampling equipment, measurement and sampling procedure, laboratory analysis, and computation procedure do not give exact results. A change in the measurement and sampling equipment, the measurement and sampling procedure, the laboratory analysis, and the computation procedure can result in a significant deviation in the quality of the data.

The accuracy requirement for the different uses of suspended-sediment data is different. On the one hand, a geomorphological study may require only a "right ball park" estimate of the suspended-sediment discharge. On the other hand, an evaluation of the precise impact of humans may require accurate information on suspended-sediment discharge.

Generally, increasing sampling frequency increases the accuracy of a record of suspended-sediment discharge until the accuracy reaches a maximum level. At this point, deviations from true values represent random errors resulting from turbulent fluctuations in streamflow and sediment movement and random and systematic errors due to instrumentation, sampling technique, and computation. If funds were available, unlimited data of a quality equal to the maximum level of accuracy could be obtained; this approach could result in excessive expenditure of funds. 
A method that could be used to relate program objectives and accuracy to sampling frequency, to document the maximum attainable accuracy at a site, and to readily appraise the accuracy of sediment records in general would be a valuable tool in the design of an optimum sediment-sampling program. The development of the method would be a step toward the improvement of the quality control of suspendedsediment data.

\section{PURPOSE AND SCOPE}

The primary purpose of this report is to present procedures that can be used to roughly appraise the accuracy of suspended-sediment data. Because the computation of suspended-sediment discharge at a site on a stream involves the approximation of suspendedsediment concentration in the vertical, across the stream, and in time, the procedures described in this report encompass errors for the three dimensions and for the suspended-sediment discharge. As defined for this study, the types of error involved are

1. Sampling error-error introduced in obtaining a value representing suspended-sediment concentration for a sample taken at a single vertical during sampling time $T_{s}$.

2. Spatial error-error in mean concentration that is determined from sampled concentrations at several verticals in a cross section for a point in time.

3. Temporal error-error in computed values of suspended-sediment concentration for a cross section for any point in time.

4. Sediment-discharge error-error in computed values of suspended-sediment discharge for a cross section for any point in time.

The four types of error do not encompass the inaccuracy or difference that results from a common situation-suspended-sediment samples usually represent sediment concentration of the flow exclusive of the bottom 0.3 to 0.5 foot of depth at each vertical. This difference between the suspended-sediment concentration for the sampled zone and for the total flow results from the omission of the suspended-sediment discharge near the streambed, where the concentration of suspended sediment, especially the coarse sediment, is highest. As the difference is largely coarse sediment, it often is significant in studies of channel behavior but usually is not significant in studies involving fine material (Bruce R. Colby, written commun., 1963).

The four types of error are treated separately in this report; however, as will be discussed, they are not mutually independent. The standard error of estimate is the statistic used to represent the errors. As will be discussed, the magnitude of the standard spatial error, the standard temporal error, and the standard sediment-discharge error depends on the sampling procedure used to obtain the mean concentration for a section. For this report, the procedures for sampling to obtain the mean concentration are called "multivertical," "single vertical," and "single point."

The standard error of estimate, representing only a random error, is a weighted measure of the difference between computed and true values of a parameter. However, the total error in a computed value may encompass both a random error and a bias error. The random error represents the randomly distributed deviations of computed values around the true value of a parameter. The random error in computed values of suspended sediment is assumed to be normally distributed about zero; therefore, the sum of errors for an unlimited number of computed values of suspended sediment would be zero. Thus, if an unlimited number of computed values of suspended-sediment concentrations at a site were available, approximately two-thirds of the observations would be within one standard error of the true values of the concentrations.

The bias error is a time-invariant deviation resulting from a consistent overestimate or a consistent underestimate of the true value of a parameter. The error that is introduced when the mean concentration for the sampled zone is used to represent the mean concentration for the total flow at a cross section is likely to be a bias error. Unless otherwise stated, bias errors are not considered in this report. Further discussions of bias and unbiased errors can be found in textbooks dealing with statistical analysis (Dixon and Massey, 1957).

The approach used in appraising the accuracy of suspended-sediment data requires that a standard error for each component (task, step, or part) of the method used to derive the suspended-sediment data be computed, approximated, or assumed. Errors for the different components must be expressed in the same units. In this report, errors are expressed in percent of true value; however, unless otherwise stated, logarithmic units were used in the analyses for error. Data used in the application of the different procedures for appraising error were obtained from published reports or from the files of the U.S. Geological Survey offices. Terms introduced in the report are defined when they are first used.

\section{SAMPLING ERROR}

\section{DISCUSSION OF ERROR}

Sampling error, as previously indicated, is the difference between the sampled and the true suspended-sediment concentration at a single vertical for the sampling time, $T_{s}$. In terms of concentration in milligrams per liter, an equation for sampling error is 


$$
R_{s v}=C_{t v}-C_{s v}
$$

in which

$R_{s v}=$ difference between true and sampled mean concentration for a single vertical during sampling time, $T_{s}$;

$C_{t v}=$ true mean concentration for the vertical during sampling time, $T_{s} ;$ and

$C_{s v}=$ sampled mean concentration for the vertical during sampling time, $T_{s}$.

The subscript $s$ denotes a parameter for a sampled value, and the subscript $t$ denotes a true value. The subscript $v$ denotes a parameter for a single vertical. As previously stated, bias errors are ignored.

The magnitude of the sampling error depends on the accuracy of the components or tasks of sampling. The components or tasks of sampling are instrument, technique (including sampling time and the fluctuation in sediment concentration during this time), laboratory analysis, and computation of concentration for the sampled water-sediment mixture.

Probably the largest part of the sampling error is introduced during the task of obtaining a water-sediment sample in the stream. As previously indicated, the objective is to obtain a representative sample of the sediment-water mixture moving in the stream in the vicinity of the sampler. This is often difficult when the stream is carrying a relatively large concentration of sand-sized sediment. Mainly because of the fluctuation of the concentration of sand-sized sediments and differences in sampling technique, the magnitude of the sampling error may vary considerably with time and among several hydrologists sampling at a vertical during a given storm event at a site on a stream. Even though other factors affecting the accuracy of sampling may be the same, the magnitude of the sampling error may be significantly different among the different types of suspended-sediment samples obtained.

Suspended-sediment samplers are of three general types-integrating samplers, instantaneous samplers, and pumping samplers (U.S. Geological Survey, 1977). Integrating samplers accumulate a water-sediment mixture over a period of time by withdrawing it from the ambient flow through a relatively small nozzle. Instantaneous, or grab, samplers essentially trap a volume of the suspension by instantaneously closing off the ends of a flow through chamber. Pumping samplers withdraw a mixture of the suspension through an intake by a pumping action. This report is concerned with integrating and pumping samplers.

An integrated sample may be of two types-depth integrated and point integrated. A depth-integrated sample is obtained as a depth-integrating sampler is lowered to the bottom of a stream and raised back to the surface. The sampler accumulates a water-sediment sample from a stream vertical at such a rate that the velocity in the nozzle at points of intake is nearly identical with the immediate stream velocity (isokinetically sampled). The sampler must be moved at a uniform rate in a given direction but not necessarily at equal rates in both directions. Significant error in the amount of sediment trapped in the sampler may result if the sampler is not lowered or raised at a uniform rate, if the sampler is lowered or raised too rapidly, or if the sampler is allowed to rest momentarily on the channel bed. Gouging or dipping the nozzle into the face of a dune is a special problem that must be avoided in order to minimize the magnitude of errors.

Standard point-integrating samplers frequently are used as depth-integrating samplers where stream depth exceeds about 17 feet, or where the stream is too swift to use a standard depth-integrating sampler (U. S. Inter-Agency Committee on Water Resources, 1943). For streams less than about 30 feet deep, the full depth can be sampled by integrating from the surface to the bottom only or from the bottom to the surface; if the stream is deeper than about 30 feet, the vertical must be integrated by parts. Significant error in the amount of sediment in the sample may result if the sampler is not lowered or raised at a uniform rate through each part of the vertical or is lowered or raised too rapidly, if the sampler is allowed to rest momentarily on the channel bed, or if the intake valve is not opened at the correct time.

A point-integrated sample is taken by holding the intake valve of a point-integrating sampler open only at selected points in a vertical. Four or five samples at selected points in a vertical usually are adequate to define the distribution of sediment in the vertical when a stream is too deep or too swift to sample by integra-. tion of a round trip from the water surface to the bottom of the stream and back to the surface.

Determination of suspended-sediment discharge at a section when samples are obtained at a single elevation in a vertical by use of a pump sampler usually does not require that the mean suspended-sediment concentration for the vertical be evaluated. The usual approach is to determine the concentration at the elevation in the vertical and to multiply that value by a coefficient to arrive at an estimate of the mean concentration for the section. Therefore, the sampling error for the sample obtained by the pump sampler is not discussed further in this section. Brief referral to the sampling error for the pump sample, however, is made in the section "Spatial Error."

\section{APPROACH TO SOLUTION}

The standard sampling error $\left(S E_{s v}\right)$ for different water and sediment-transport regimes can be ap- 
praised using data in the files of the U.S. Geological Survey. The data useful for the purpose consist of sets of two depth-integrated samples for a single vertical in a stream taken as close together in time as possible (Guy and Norman, 1970). Individual analyses of sediment concentration yield two complete samples for the sampling time, $T_{s}$ (fig. 1), which usually is no more than 2 to 4 minutes. As indicated in figure $1, C_{s v_{1}}$ represents the concentration for the first sample, $C_{s v_{2}}$ represents the concentration for the second sample, $C_{t v}$ represents the true mean concentration during $T_{s}, R_{s v_{1}}$ represents the difference between $C_{s v_{1}}$ and $C_{t v}$, and $R_{s v_{2}}$ represents the difference between $C_{s v_{2}}$ and $C_{t v}$.

The variance of the difference between the two sampled concentrations may be estimated as follows:

$$
\begin{aligned}
(S E)_{s v_{1-2}}^{2} & =\frac{\sum\left[C_{s v_{1}}-C_{s v_{2}}\right]^{2}}{N} \\
& =\frac{\sum\left[\left(C_{t v}+R_{s v_{1}}\right)-\left(C_{t v}+R_{s v_{2}}\right)\right]^{2}}{N} \\
& =\frac{\sum\left(R_{s v_{1}}-R_{s v_{2}}\right)^{2}}{N}
\end{aligned}
$$

in which $N$ is the number of pairs of samples. The expected value is represented as

$$
E\left[(S E)_{s v_{1-2}}^{2}\right]=\sigma_{s v_{1}}^{2}+\sigma_{s v_{2}}^{2}=2 \sigma_{s v}^{2}
$$

if the sampling errors for the two samples are independent. In that case, the expected value for $S E_{s v}^{2}$ can be represented as

$$
E\left[(S E)_{s v}^{2}\right]=\frac{E\left[(S E)_{s v_{1-2}}^{2}\right]}{2}=\sigma_{s v}^{2} .
$$

Equation 4 can be used for any pair of depthintegrated or point-integrated samples. However, the only "paired" samples available for this study were those for the depth-integrated sample. For this study, the standard sampling error for samples obtained using a point-integrating sampler is assumed to be equal to that for samples obtained using a depthintegrating sampler, and the error for samples collected using the point-integrating sampler is not considered further.

\section{APPLICATION OF METHOD}

\section{BASIC DATA}

Sediment records for five gaging stations on the Sacramento River (stations with reference numbers 2, $3,4,5$, and 6 in table 1) and two gaging stations on streams tributary to the Sacramento River (reference numbers 14 and 16) were selected for the present study primarily because they were readily accessible and contained the required data in a usable form. Extremes in daily discharge and daily sediment concentration for the study period at the seven stations are given in table 1. Complete descriptions of the characteristics of the flow and sediment regimes for the seven stations can be found in the files of the California District Office, U.S. Geological Survey, Water Resources Division, Sacramento, Calif. Data for the 1977-79 study period were used for the analysis of error.

The data useful for appraising the magnitude of the standard sampling error for each of the seven gaging sites (table 1), as previously indicated, consist of sets of two depth-integrated samples for a single vertical taken as close together in time as possible. The two samples for a given observation were obtained because they were useful to the fieldman and to the office engineer to indicate the variation of concentration between samples-an advantage if the concentration for one of the samples were in obvious error. A large amount of sediment in one of the samples may indicate that the sampler was lowered into uncompacted sediment moving slowly along the bed; it.would not be indicative of suspended material. The office engineer responsible for computing sediment discharge will not use the results from a sample for which the concentration is obviously in error. Usually, only a small percentage of the data for a station is rejected by the office engineer. Data for samples not used are labeled as such.

Data rejected by the office engineer also were rejected for the current study. The screening of the data in this fashion may result in the standard error of estimate being biased on the low side. However, failure to reject samples containing large amounts of bed material probably would have resulted in a larger bias on the high side being introduced.

After screening, 212 sets of samples remained. Results of particle-size analyses were available for most of these sets. The distribution of the sets among the seven stations is shown in column 10 of table 1 .

\section{STANDARD SAMPLING ERROR}

The same analytical procedure was used to appraise the standard sampling error for data for each of the seven gaging stations. The data set for each station was divided into groups according to ranges of percentage 


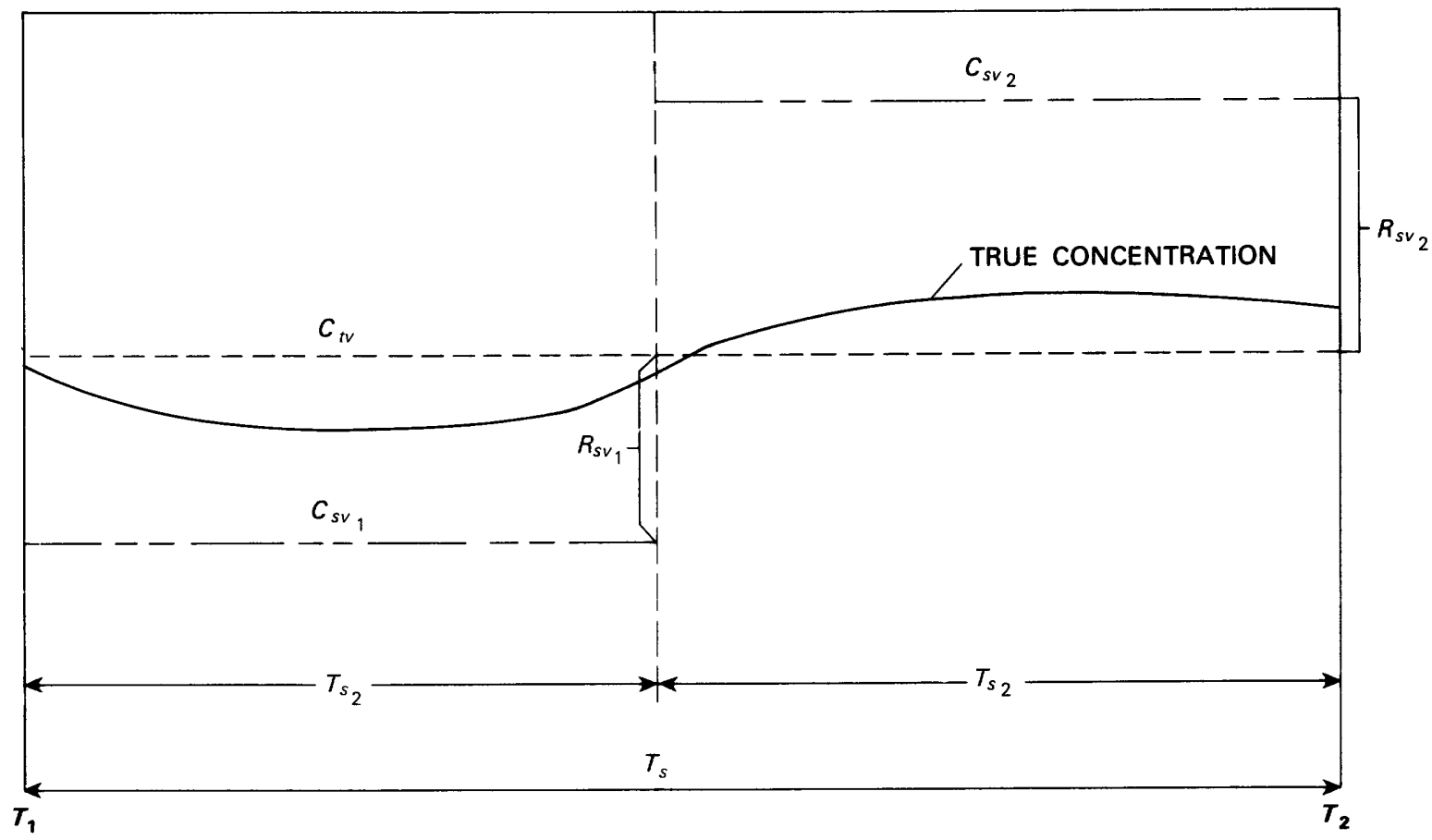

FIGURE 1.-Schema of assumed true concentration at a vertical during $T_{2}-T_{1}$, with nomenclature.

sand in the sampled mixture. For each station, the variance of the difference between the two sampled concentrations, $S E_{s v_{1-2}}^{2}$, was computed for each group of samples by using equation 2 . An estimate of the standard sampling error, $S E_{s v}$, for each group was obtained by using equation 4 . As stated previously, logarithms of the concentrations were used in the analyses to determine variance. Data were adequate to define errors for two ranges of percentage sand for each of the study stations except one-Sacramento River above Bend Bridge near Red Bluff, Calif.

Results of analyses to appraise the standard sampling error are given in table 1 and in figure 2. The numbers for percentage sand that are shown in table 1 (column 11) represent the average of values (percentage sand) for the different groups of data. The numbers for percent error in table 1 (column 12) represent the (absolute) average of positive and negative values that result when logarithmic units are used to compute error.

The curves in figure 2 were developed from the following equation:

$$
S E_{s v}=\left(k_{f}\right) \times(\% F)+\left(k_{s}\right) \times(\% S),
$$

in which

$S E_{s v}=$ standard sampling error, in percent;

$\% F=$ percentage fines;

$\% S=$ percentage sand; and

$k_{f}, k_{s}=$ coefficients.
The quantity $k_{f}$ represents the standard sampling error as a fraction, when the suspended mixture is 100 percent fines; $k_{s}$ represents the error when the mixture is 100 percent sand.

Equations 5A, 5B, 5C, and 5D, shown with the lines in figure 2, were developed from equation 5 using 0.025 for $k_{f}$ and $0.25,0.20,0.15$, and 0.10 , respectively, for $k_{s}$. For the data from sites on the Sacramento River and Cottonwood Creek, equation $5 \mathrm{~B}$, based on 0.025 for $k_{f}$ and 0.20 for $k_{s}$, seems to agree with the plotted values. This agreement apparently indicates that the standard sampling error for the Sacramento River and Cottonwood Creek may be as small as 2.5 percent for periods when the percentage of the suspended sediment that is sand is relatively low and as large as 20 percent when the percentage sand is relatively high. For the Thomes Creek site, the extreme values for standard sampling error may be 2.5 and 13 percent.

\section{SPATIAL ERROR}

\section{DISCUSSION OF ERROR}

\section{INTRODUCTION}

Spatial error is the difference between the sampled and the true mean suspended-sediment concentration for a cross section for the sampling period (i.e., the time when the samples were obtained). In terms of concentration in milligrams per liter, an equation for the spatial error is 
TABLE 1.-Estimates of standard errors and information related to errors for selected sites along selected

\begin{tabular}{|c|c|c|c|c|c|c|c|c|}
\hline \multirow{3}{*}{$\begin{array}{l}\text { Refer- } \\
\text { ence } \\
\text { (1) }\end{array}$} & \multirow{3}{*}{$\begin{array}{l}\text { Sym- } \\
\text { bol } \\
\text { (2) }\end{array}$} & \multirow{3}{*}{ Gaging station or site } & \multirow{3}{*}{$\begin{array}{c}\text { Study period } \\
\text { (period of } \\
\text { record used } \\
\text { in analyses) } \\
(4)\end{array}$} & \multirow{3}{*}{$\begin{array}{l}\text { Source of data } \\
\text { (5) }\end{array}$} & \multicolumn{4}{|c|}{ Extremes during study period } \\
\hline & & & & & \multicolumn{2}{|c|}{$\begin{array}{c}\text { Daily discharge } \\
\text { (cubic feet } \\
\text { per second) } \\
\end{array}$} & \multicolumn{2}{|c|}{$\begin{array}{r}\text { Daily sediment } \\
\text { concentration } \\
\text { (milligrams/liter) } \\
\end{array}$} \\
\hline & & & & & $\begin{array}{l}\text { High } \\
(6)\end{array}$ & $\begin{array}{l}\text { Low } \\
(7)\end{array}$ & $\begin{array}{r}\text { High } \\
(8)\end{array}$ & $\begin{array}{l}\text { Low } \\
(9)\end{array}$ \\
\hline 1 & A & $\begin{array}{l}\text { Sacramento River at Keswick, } \\
\text { Calif. (11370500) }\end{array}$ & $\begin{array}{l}11 / 16 / 77 \text { to } \\
10 / 05 / 78\end{array}$ & $\begin{array}{l}\text { Files, California } \\
\text { District, WRD, USGS, } \\
\text { Sacramento, Calif. }\end{array}$ & 39,000 & 2,460 & -- & -- \\
\hline 2 & B & $\begin{array}{l}\text { Sacramento River above Bend } \\
\text { Bridge near Red Bluff, Calif. } \\
(11377100)\end{array}$ & $\begin{array}{l}11 / 02 / 77 \text { to } \\
01 / 18 / 80\end{array}$ & do. & 106,000 & 3,200 & 2,320 & 1 \\
\hline 3 & C & $\begin{array}{l}\text { Sacramento River at Hamilton } \\
\text { City, Calif. (11383800) }\end{array}$ & $\begin{array}{l}11 / 02 / 77 \text { to } \\
01 / 18 / 80\end{array}$ & do. & 110,000 & 3,000 & 1,030 & 6 \\
\hline 4 & $\mathbf{D}$ & $\begin{array}{l}\text { Sacramento River at Butte } \\
\text { City, Calif. }(11289000)\end{array}$ & $\begin{array}{l}11 / 03 / 77 \text { to } \\
06 / 06 / 79\end{array}$ & do. & 121,000 & 2,720 & 1,630 & 8 \\
\hline 5 & $\mathbf{E}$ & $\begin{array}{l}\text { Sacramento River at Colusa, } \\
\text { Calif. (11389500) }\end{array}$ & $\begin{array}{l}11 / 04 / 77 \text { to } \\
06 / 12 / 79\end{array}$ & do. & 45,200 & 2,620 & 2,000 & 10 \\
\hline 6 & $\mathbf{F}$ & $\begin{array}{l}\text { Sacramento River at Knights } \\
\text { Landing, Calif. (11391000) }\end{array}$ & $\begin{array}{l}11 / 01 / 77 \text { to } \\
01 / 07 / 80\end{array}$ & do. & 29,700 & 2,980 & 990 & 19 \\
\hline 7 & 0 & Niobrara River near Cody, Neb. & $\left({ }^{3}\right)$ & $\begin{array}{l}\text { Colby and Hembree, } \\
1955\end{array}$ & $\left({ }^{3}\right)$ & $\left({ }^{3}\right)$ & $\left({ }^{3}\right)$ & $\left({ }^{3}\right)$ \\
\hline 8 & $\odot$ & $\begin{array}{l}\text { Middle Loup River near } \\
\text { Dunning, Neb. }\end{array}$ & $\left({ }^{3}\right)$ & $\begin{array}{l}\text { Hubbell and others, } \\
1956 ; \text { Hubbell and } \\
\text { Matejka, } 1959 \text {. }\end{array}$ & $\left({ }^{3}\right)$ & $\left({ }^{3}\right)$ & $\left({ }^{3}\right)$ & $\left({ }^{3}\right)$ \\
\hline 9 & $\otimes$ & $\begin{array}{l}\text { Middle Loup River below } \\
\text { Dismal River, Neb. }\end{array}$ & $\left({ }^{3}\right)$ & Hubbell, 1960 & $\left({ }^{3}\right)$ & $\left({ }^{3}\right)$ & $\left({ }^{3}\right)$ & $\left({ }^{3}\right)$ \\
\hline 10 & 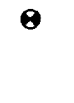 & $\begin{array}{l}\text { Cowlitz River at Castle } \\
\text { Rock, Wash. }\end{array}$ & $01 / 14 / 81$ & $\begin{array}{l}\text { Files, Washington } \\
\text { District, WRD, USGS, } \\
\text { Tacoma, Wash. }\end{array}$ & $\left({ }^{3}\right)$ & $\left({ }^{3}\right)$ & $\left({ }^{3}\right)$ & $\left({ }^{3}\right)$ \\
\hline 11 & $\phi$ & $\begin{array}{l}\text { Colorado River near Grand } \\
\text { Canyon, Ariz. }\end{array}$ & $\left({ }^{3}\right)$ & Howard, 1947 & $\left({ }^{3}\right)$ & $\left({ }^{3}\right)$ & $\left({ }^{3}\right)$ & $\left({ }^{3}\right)$ \\
\hline 12 & $\theta$ & $\begin{array}{l}\text { Rio Grande Conveyance } \\
\text { Channel near Bernardo, N.Mex. }\end{array}$ & $\left({ }^{3}\right)$ & $\begin{array}{l}\text { Culbertson, Scott, } \\
\text { and Bennett, } 1972\end{array}$ & $\left({ }^{3}\right)$ & $\left({ }^{3}\right)$ & $\left({ }^{3}\right)$ & $\left({ }^{3}\right)$ \\
\hline 13 & $x$ & $\begin{array}{l}\text { Cow Creek near Millville, } \\
\text { Calif. }(11374000)\end{array}$ & $\begin{array}{l}11 / 08 / 77 \text { to } \\
05 / 24 / 78\end{array}$ & $\begin{array}{l}\text { Files, California } \\
\text { District, WRD, USGS, } \\
\text { Sacramento, Calif. }\end{array}$ & 16,700 & 59 & 1,500 & 1 \\
\hline 14 & $\Delta$ & $\begin{array}{l}\text { Thomes Creek at Rawson Road } \\
\text { Bridge near Richfield, } \\
\text { Calif. (11382090) }\end{array}$ & $\begin{array}{l}01 / 22 / 77 \text { to } \\
04 / 04 / 79\end{array}$ & do. & 2,800 & 0 & 6,620 & 0 \\
\hline 15 & ๑ & $\begin{array}{l}\text { Feather River at Nicolaus, } \\
\text { Calif. (11425000) }\end{array}$ & $\begin{array}{l}11 / 09 / 78 \text { to } \\
05 / 21 / 79\end{array}$ & do. & 27,200 & 2,130 & 217 & 12 \\
\hline 16 & $\otimes$ & $\begin{array}{l}\text { Cottonwood Creek near } \\
\text { olinda, Calif. (11375810) }\end{array}$ & $\begin{array}{l}10 / 04 / 77 \text { to } \\
03 / 02 / 79\end{array}$ & do. & 10,100 & 9.1 & 3,600 & 0 \\
\hline 17 & - & Bixler Run near Loysville, $\mathrm{Pa}$. & $\begin{array}{l}03 / 12 / 62 \text { to } \\
03 / 15 / 62\end{array}$ & $\begin{array}{l}\text { Files, Pennsylvania } \\
\text { District, WRD, USGS, } \\
\text { Harrisburg, Pa. }\end{array}$ & 132 & 88 & 616 & 8 \\
\hline
\end{tabular}

${ }^{1}$ Standard spatial error computed from values of concentration obtained by sampling at multiverticals.

${ }^{2} \mathrm{Standard}$ spatial error based on standard spatial error for the concentration at one vertical and the standard error for the correction factor in equation $12 \mathrm{~A}$.

${ }^{3}$ See source of data for information about the period of record and extremes during study period.

${ }^{4}$ Composite value for two cross sections.

${ }^{5}$ Composite value for several cross sections. 
rivers and streams in California, Nebraska, Washington, Arizona, New Mexico, and Pennsylvania

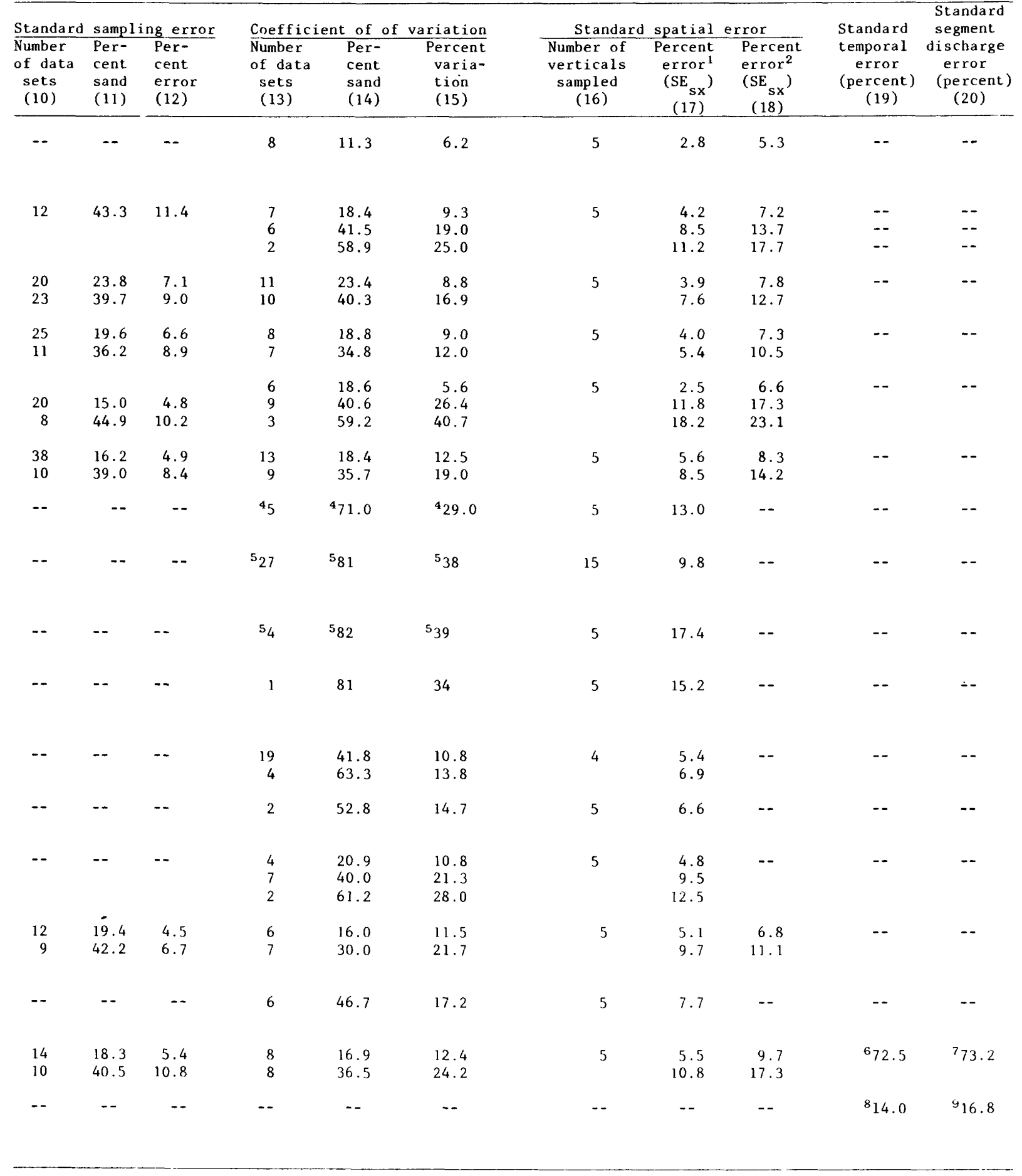

${ }^{6}$ The value was obtained from the curve in figure 4 for an elapsed time of 4.5 hours.

${ }^{7}$ Based on 72.5 percent for the standard temporal error and 10 percent for the standard error for water discharge.

${ }^{8}$ The value was obtained from the curve in figure 4 for an elapsed time of 1.2 hours.

${ }^{9}$ Based on 13.5 percent for the standard temporal error and 10 percent for the standard error for water discharge. 


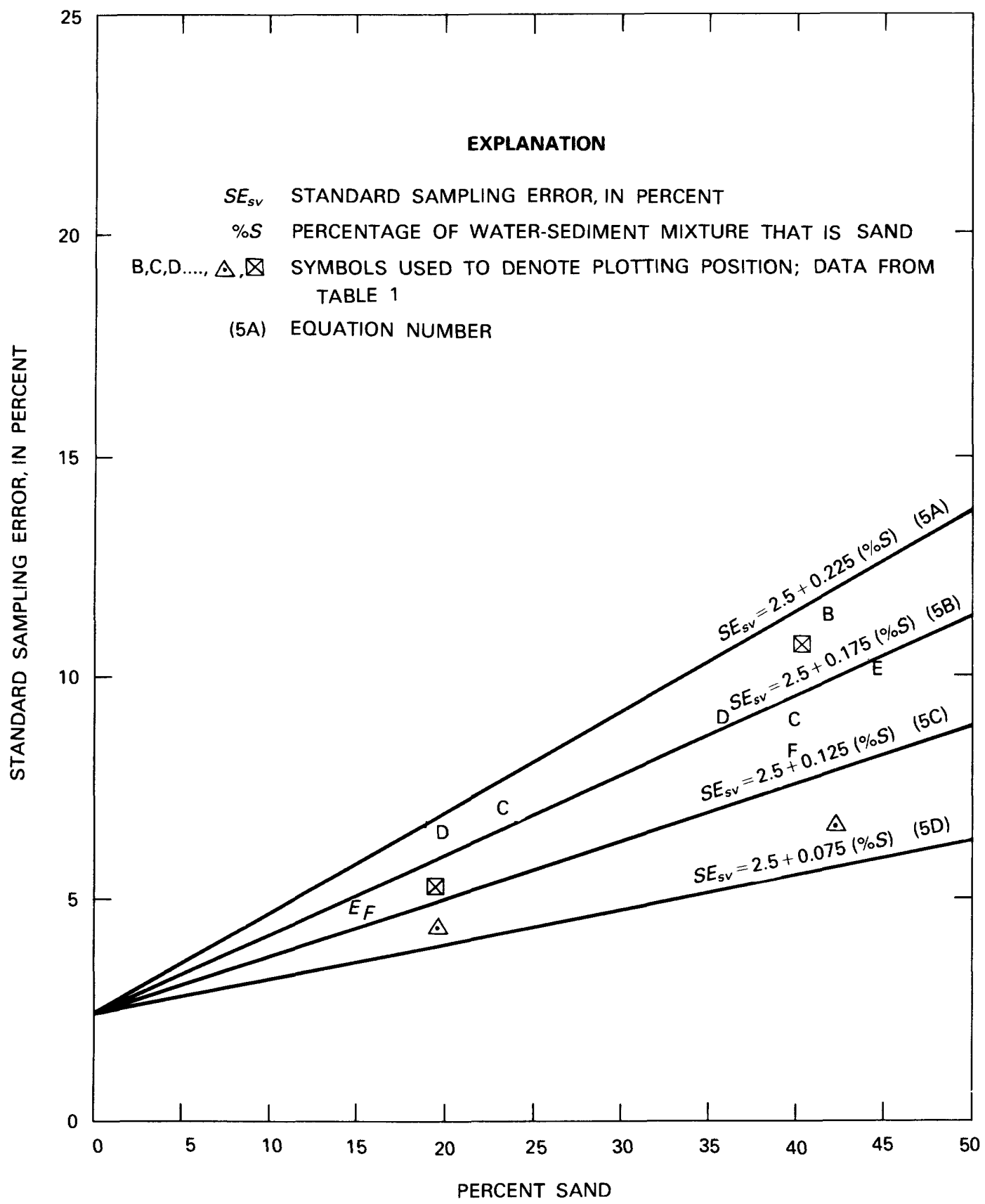

FIGURE 2.-Relation between standard sampling error and percentage sand in the sampled water-sediment mixture.

$$
R_{s x}=C_{t x}-C_{s x}
$$

in which

$R_{s x}=$ difference between sampled and true mean concentration for a cross section;

$C_{t x}=$ true mean concentration for the cross section; and

$C_{s x}=$ sampled mean concentration for the cross section.
The subscript $x$ denotes a parameter for a cross section.

The magnitude of the spatial error typically depends on the natural variability of the suspended-sediment concentration with distance across the section, on the procedure for sampling that is used to obtain the mean concentration for a section, on the number of verticals when a multivertical procedure is used, and on the type of sample obtained at the verticals. 
The natural variability of suspended-sediment concentration across a stream depends on several interrelated factors. Some of the factors are hydraulic geometry (width, depth, and velocity) of the flow; channel-bed form (ripple, dunes, transition, plane, antidunes, and chute and pool); alinement of channel and flow; distance downstream from confluence with tributary stream; supply of clay-, silt-, sand-, and gravel-sized sediments; percentage of total concentration that is sand; and temperature of water. The procedures for sampling, as previously mentioned, are multivertical, single vertical, and single point.

\section{MULTIVERTICAL PROCEDURE}

To determine the mean concentration at a section by the multivertical procedure, samples of the sedimentwater mixture are obtained periodically at three or more verticals in the section. These samples usually are combined to give a representative sample for the section. Concentration of suspended sediment for the representative sample is evaluated by laboratory analysis, and is assumed to represent the mean for the section (Porterfield, 1972). The verticals can be spaced so that they represent either equal rates of discharge-the EDI approach-or equal distance across the section with an equal-transit-rate (ETR) sample at each vertical-the EWI approach (Guy and Norman, 1970; U.S. Geological Survey, 1977). As previously indicated, the accuracy of the mean concentration obtained by the multivertical procedure depends on the natural variability of the suspended-sediment concentration across the section, the number of verticals sampled, and the sampling errors.

\section{SINGLE-VERTICAL PROCEDURE}

To approximate the mean concentration at a section using the single-vertical procedure, samples of the sediment-water mixture are obtained periodically at a permanently located vertical in the section (Porterfield, 1972). Occasionally, samples of the sedimentwater mixture are obtained at three or more verticals at a time when a sample is obtained at the permanently located vertical. Typically, the samples for the three or more verticals are combined to give a representative verification sample. Concentrations of suspended sediment for the verification sample and for the singlevertical sample are evaluated by laboratory analyses. Ratios are computed by dividing the concentration for the verification sample by the concentration for the single-vertical sample. This ratio represents a correction, called a cross-section coefficient for this study, to be applied to the single-vertical concentration to obtain a value that represents a mean concentration for the section. A temporal concentration curve for the single vertical is developed, as is a temporal curve represent- ing the cross-section coefficient. A mean concentration for the section for the time when a single-vertical sample is obtained can be approximated by multiplying the concentration for the single vertical by a value for the time obtained from the temporal cross-section coefficient curve.

The accuracy of the mean concentration obtained by using the single-vertical approach typically depends on the magnitude of errors for the single-vertical sample and on how well values taken from the temporalcoefficient curve represent the true cross-section coefficient.

Records of concentration are obtained for some sites based on an assumption that the cross-section coefficient is always 1 . Obviously, the error in the data would depend on how well the concentration for the single vertical represents the mean concentration for the section. The data, however, may contain a bias error. The scope of the present study, as previously indicated, does not include analyses to determine the magnitude of the bias error. Intuitively, however, it would appear that the bias error can be relatively large for sites where a relatively large percentage of the suspended sediment is in the sand-sized range.

\section{SINGLE-POINT PROCEDURE}

Steps for determining mean concentration at a section for any point in time using the single-point procedure are the same as those for the single-vertical procedure except that when using the single-point method, samples typically are obtained at only a single stage in the vertical. The point sample, which gives an indication of the sediment-water mixture moving at a single point in a vertical in a stream, usually is obtained automatically by using a pumping-type sampler which does not sample isokinetically. The single-point sample typically is obtained at stations in flashy streams or at other locations where it is extremely difficult to reach a station to collect samples manually at appropriate times by the normal procedure with standard equipment.

The automatic sampler is positioned in the stream before a flow event occurs. The automatic sampler, because of its many limitations, is not used indiscriminately to obtain samples, especially in streams carrying significant amounts of sand-sized sediment. Specific limitations of the point sample and automatic samplers, which usually apply to the sampling of sandsized sediment more than to fine sediments, are given in a report by Skinner and Beverage (1981).

The accuracy of the mean concentration for a section at times when single-point samples were obtained depends on the magnitude of errors for the single-point sample and for the correction coefficient. 


\section{APPROACH TO SOLUTION}

\section{MULTIVERTICAL PROCEDURE}

The approach used to approximate the magnitude of the standard spatial error for data obtained using the multivertical procedure involves mean concentrations, standard deviations for the means, and coefficients of variations for suspended sediment at cross sections (Guy, 1968). In terms of concentration in milligrams per liter, the equation for the mean concentration for a cross section is

$$
C_{s x}=\left(1 / N_{1}\right) \sum_{i=1}^{N_{1}} C_{s v_{i}},
$$

in which $N_{1}$ is used to represent the number of verticals with a single sample at each in the cross section. The standard deviation, $(S D)_{s x}$, in milligrams per liter, can be represented as

$$
(S D)_{s x}=\sqrt{\frac{\sum_{i=1}^{N_{1}}\left[\left(C_{s x}+D_{s x}\right)_{i}-\left(C_{s x}\right)_{i}\right]^{2}}{N_{1}-1}}=\frac{\sum_{i=1}^{N_{1}} D_{s x_{i}}^{2}}{N_{1}-1}
$$

in which the quantity $\left(C_{s x}+D_{s x}\right)$ is used to represent $C_{s v}$, the concentration for a single sample at a single vertical, and $D_{s x}$ is used to represent a departure from the mean concentration for the cross section, $C_{s x}$. The coefficient of variation, in percent, is represented as

$$
(C V)_{s x}=\frac{100\left(S D_{s x}\right)}{C_{s x}}
$$

An approximation of the spatial standard error of estimate, in percent, is represented as

$$
(S E)_{s x}=\frac{(C V)_{s x}}{\sqrt{N_{1}}}
$$

It should be noted that the variance $(S D)_{s x}^{2}$ is an approximation of the sum of two variances: $\left(S E_{s v}\right)^{2}$ representing the sampling error, and $\left(S D_{n a t}\right)^{2}$ representing the natural variability of suspended-sediment concentration with distance across a stream.

\section{SINGLE-VERTICAL AND \\ SINGLE-POINT PROCEDURES}

The approach for approximating the standard spatial error for the single-vertical procedure for determining mean concentration at a cross section involves the addition of variances for the single-vertical sampling error and the cross-section coefficient. In terms of concentration in milligrams per liter, an equation for mean concentration for a section, according to the single-vertical procedure, can be represented as

$$
C_{e x}=(a) C_{s v},
$$

in which

$$
\begin{aligned}
& C_{e x}= \text { estimated mean concentration for a cross sec- } \\
& \text { tion when a suspended-sediment sample at a } \\
& \text { vertical is available, and } \\
& a=a \text { variable cross-section coefficient. }
\end{aligned}
$$

The subscript $e$ denotes an estimated parameter. Values for $a$ are obtained from a temporal curve that represents the cross-section coefficient (page 9 ). In order that variances representing $a$ and $C_{s v}$ be additive, equation 11 must be used in its logarithmic form, $\log \left(C_{e x}\right)$ $=\log a+\log C_{s v}$. In units of $\log$ arithms, the variance for $C_{e x}$ can be represented as

$$
\left[\left(S E_{\log }\right)_{e x}\right]^{2}=\left[\left(S E_{\log }\right)_{a}\right]^{2}+\left[\left(S E_{\log }\right)_{s v}\right]^{2}
$$

in which

$\left(S E_{\mathrm{log}}\right)_{e x}=$ standard spatial error in logarithmic units when the single-vertical procedure is in use,

$\left(S E_{\log }\right)_{a}=$ standard error for the cross-section coefficient $a$, in logarithmic units, and

$\left(S E_{\log }\right)_{s v}=$ standard sampling error, in logarithmic units.

The variance when the concentration at a single point is used to represent the mean for a section can be represented as

$$
\left[\left(S E_{\log }\right)_{e x_{1}}\right]^{2}=\left[\left(S E_{\log }\right)_{a_{1}}\right]^{2}+\left[\left(S E_{\log }\right)_{p}\right]^{2}
$$

in which

$$
\begin{aligned}
\left(S E_{\log }\right)_{e x_{1}}= & \text { standard spatial error in logarithmic } \\
& \text { units when the single-point procedure } \\
& \text { is used, } \\
\left(S E_{\log }\right)_{a_{1}}= & \text { standard error for the coefficient } a_{1} \text {, in } \\
& \text { logarithmic units }\left(a_{1}\right. \text { represents a cor- } \\
& \text { rection coefficient when the concentra- } \\
& \text { tion for a single point in a vertical is } \\
& \text { used to represent the mean for a sec- } \\
& \text { tion), and } \\
\left(S E_{\log }\right)_{p}= & \text { standard error for the concentration ob- } \\
& \text { tained at a single point in a vertical, in } \\
& \text { logarithmic units. }
\end{aligned}
$$

The subscript $p$ denotes a parameter for a single point in time. 


\section{APPLICATION OF METHOD}

\section{BASIC DATA}

Sediment records for 16 gaging stations were selected to demonstrate the procedure for appraising the standard spatial error (table 1). The records are for stations on the Sacramento River and tributary streamsFeather River and Thomes, Cow, and Cottonwood Creeks in California, Niobrara and Middle Loup Rivers in Nebraska, Cowlitz River in Washington, Colorado River in Arizona, and the Rio Grande Conveyance Channel in New Mexico. These records were selected mainly because they were readily available and contained the type of data that were needed. They also represented a wide range of hydraulic conditions and sediment-transport regimes. Sets of data representing the concentration at four or more verticals were available at one or more cross sections at the stations.

Descriptions of the lengths of the study period and the ranges in discharge and sediment concentration for the 16 study stations are given in table 1 . Further descriptions of the discharge and sediment regimes for the study stations can be found at the different sources of data.

The data useful for appraising the magnitude of spatial error consist of concentrations representing the water-sediment mixtures at multiverticals in cross sections. The data were required as a basis for describing the natural variability of the suspended-sediment concentration with distance across the streams that are involved.

\section{STANDARD SPATIAL ERROR FOR} MULTIVERTICAL PROCEDURE

For the multivertical procedure, the same analytical approach was used to appraise the standard spatial error for data for each of the 16 gaging stations. By task, the approach was as follows:

1. The data for each station were divided into groups according to ranges of percentage sand in the sampled mixture.

2. For each station, the coefficient of variation, $(C V)_{s x}$, was computed for each range. Equations 7,8 , and 9 were used for this task. This gave a coefficient of variation for each data group.

3. Values for percentage sand and values for the coefficient of variation were averaged for each data group. This gave an average percentage sand and an average coefficient of variation for each range of percentage sand (table 1).

4. An estimate of the standard spatial error, $(S E)_{s x}$, for each group (or range) was obtained by use of equation 10 .

Data were adequate to define groups representing three ranges of percentage sand for three stations, two ranges of percentage sand for six stations, and a single range for the remaining seven stations (table 1).

Results of analyses to appraise the coefficient of variation (task 2) are given in table 1 and figure $3 A$. The curves in figure $3 A$ were developed from the following equation:

$$
(C V)_{e x}=(\% F) \times\left(k_{f x}\right)+(\% S) \times\left(k_{s x}\right),
$$

in which

$$
\begin{aligned}
(C V)_{e x} & =\text { estimated coefficient of variation, in } \\
& \text { percent, } \\
\% F & =\text { percentage fines, } \\
\% S & =\text { percentage sand, and } \\
k_{f x}, k_{s x} & =\text { coefficients. }
\end{aligned}
$$

The quantity $k_{f x}$ represents the coefficient of variation, as a fraction, when the suspended mixture is 100 percent fines; $k_{s x}$ represents the coefficient when the mixture is 100 percent sand.

Equation 14 is based on an assumption that the variability of concentration across a stream increases with percentage sand in the water-sediment mixture. Even though the plotted points in figure $3 A$ scatter significantly, the data for the 16 study sites seem to support this assumption. Equations 14A, 14B, 14C, and 14D, shown with the lines in figure $3 \mathrm{~A}$, were developed from equation 14 substituting $(100-\% S)$ for $\% F$ and using 0.025 for $k_{f x}$, and $0.70,0.50,0.30$, and 0.20 , respectively, for $k_{s x}$. Apparently, the average standard coefficient of variation for the plotted data can be represented by a curve developed from equation 14 with 0.025 for $k_{f x}$ and 0.40 for $k_{s x}$.

The reason, or reasons, for the difference in rate of increase in variability in concentration with increase in percentage sand among the 16 stations is not known. A detailed study to document reasons for the difference in the rates of increase is beyond the scope of this report.

For the flow and sediment conditions at the study sites, the curves on figures $3 A$ and $3 B$ can be used as a guide to approximate the number of verticals in a section that should be sampled in order to obtain a mean concentration with a specific standard spatial error. For example, suppose the required standard spatial error was 4 percent and the section to be sampled was at the gaging station "Sacramento River above Bend Bridge near Red Bluff, Calif." Suppose further that, for two sets of flow and sediment conditions, the percentage sand and the coefficient of variation are 18.4 and 9.3 for one set of conditions, and 58.9 and 25.0 for the other set. The problem is to determine the number of verticals to be sampled in order to obtain a mean concentration with a standard spatial error of about 4 percent. According to the curves on figures $3 A$ and $3 B$, the required number of verticals to be sampled 


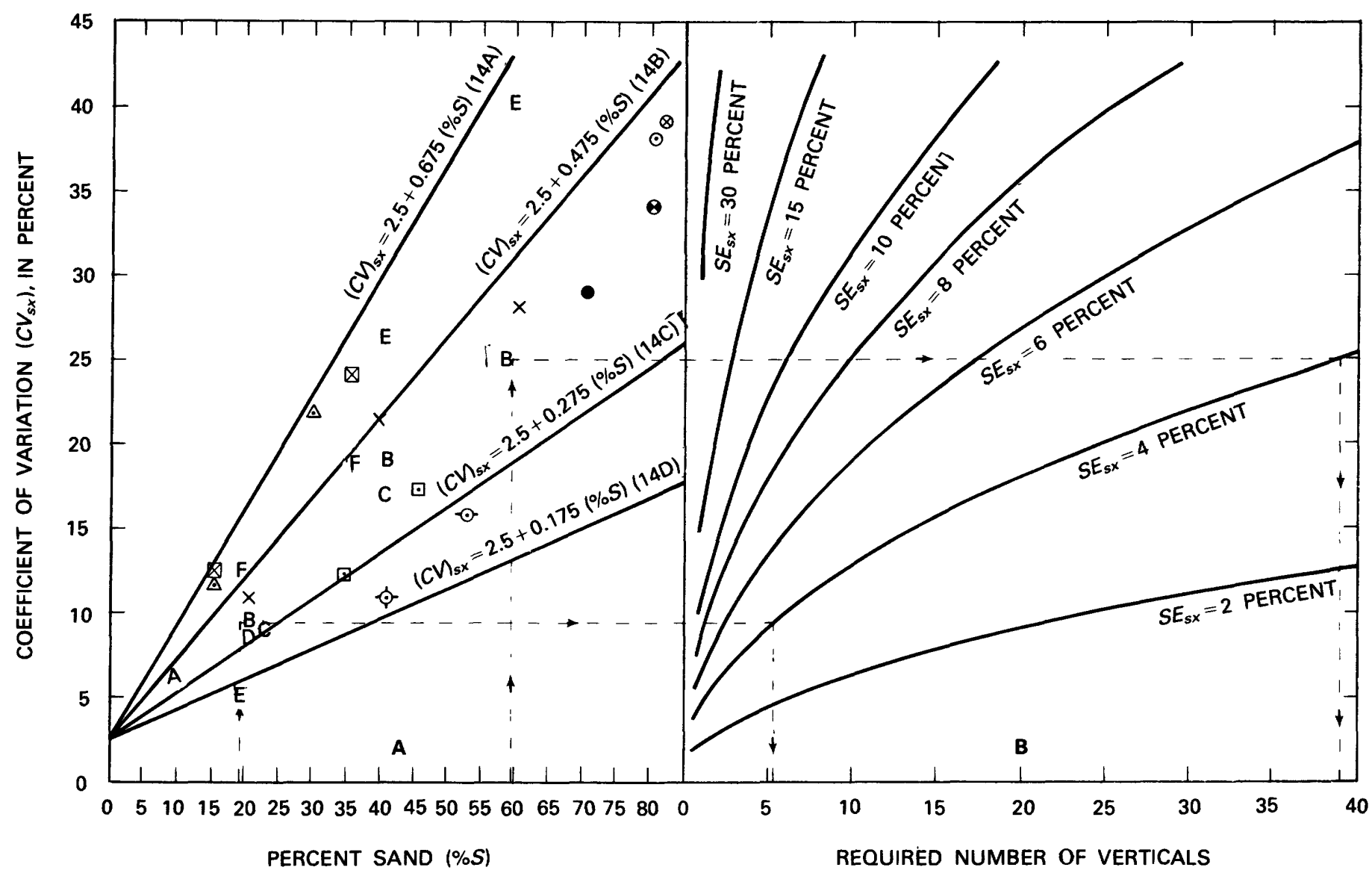

EXPLANATION

$\begin{array}{ll}\left(C \eta_{s x}\right. & \text { COEFFICIENT OF VARIATION, IN PERCENT } \\ (\% S) & \text { PERCENTAGE OF WATER-SEDIMENT MIXTURE } \\ & \text { THAT IS SAND } \\ S E_{s x} & \text { STANDARD SPATIAL ERROR, IN PERCENT }\end{array}$

$A, B, C, \ldots ., \notin, \odot \otimes$ SYMBOLS USED TO DENOTE PLOTTING POSITION, DATA FROM TABLE 1

FIGURE 3.-A, Relation between the coefficient of variation and the percentage of the sampled water-sediment mixture that is sand. B, Relation between the coefficient of variation, the standard spatial error, and the number of verticals required to obtain the indicated standard spatial error.

would be about 40 for the conditions of relatively high percentage sand and variability and about 6 for conditions of relatively low percentage sand and variability. Thus, the ratio of required verticals for the two conditions is about 7.

The ratio of the numbers of required verticals for the two types of conditions discussed in the preceding paragraph probably would be much greater than 7 for sections in streams where the percentages of suspended sediment that is sand have wide ranges. The ratio can be determined directly by use of the formula "ratio $=\left(C V_{x a} / C V_{x b}\right)^{2}$ " in which $C V_{x a}$ represents the high coefficient of variation for a site, often occurring during periods of high flow, and $C V_{x b}$ represents the low coefficient of variation for the site, often occurring during periods of low flow. Assuming that the bounding curves shown in figure $3 A$, defined from equations $14 \mathrm{~A}$ and $14 \mathrm{D}$, adequately represent extreme values of variation, the ratio of required verticals to obtain mean concentrations of a specific standard spatial error could range from 1 to 64 according to coefficients taken from the curves that bound the smallest coefficients of variation and from 1 to 784 according to coefficients taken from the curves that bound the largest coefficients of variation. For the Red Bluff site, the coefficient of variation ranged from 2.9 to 29.8 for multivertical samples taken during the study period. Using these values in the above formula, the ratio would be 106 . 
SIANDARI SPATIAL ERROR FOR SINGLE-VERTICIAL PROC:EDURE

The standard spatial error for mean concentrations obtained using the single-vertical procedure can be approximated using equation 12 , but only if numbers are available for the standard sampling error and for the standard error for the cross-section coefficient $a$. Numbers representing the standard error for the cross-section coefficient $(S E)_{a}$ for the study stations, however, are not readily available; therefore, equation 12 cannot be used directly to estimate $(S E)_{e x}$.

A discussion of the possible range in $(S E)_{e x}$ for the study stations is based on expanded versions of equations 11 and 12. The discussion is for two cases: (1) when verification samples are available and the mean concentration for a section is assumed to be equal to the concentration for a single vertical multiplied by a cross-section coefficient $a$; and (2) when the mean concentration for a section is assumed to be equal to the concentration for a single vertical (verification samples are not available and $a$ is assumed to be 1 ). The expanded version of equation 11 is

$$
C_{e x}=a_{2}\left(\frac{C_{s x_{2}}}{C_{s v_{2}}} C_{s v}\right) \text {, }
$$

in which

$a_{2}=\mathbf{a}$ variable coefficient,

$C_{s x_{2}}=$ mean concentration for a section (derived from a multivertical-verification sample); and

$C_{s v_{2}}=$ concentration at a single vertical (derived from a sample obtained at a permanently located vertical).

The expanded version of equation 12 is

$\left(S E_{\log }\right)_{e x}^{2}=\left(S E_{\log }\right)_{a_{2}}^{2}+\left(S E_{\log }\right)_{s x_{2}}^{2}+\left(S E_{\log }\right)_{s v_{2}}^{2}+\left(S E_{\log }\right)_{s v}^{2}$

or

$$
\left(S E_{\log }\right)_{e x}^{2}=\left(S E_{\log }\right)_{a_{2}}^{2}+\left(S E_{\log }\right)_{s x}^{2}+2\left(S E_{\log }\right)_{s v}^{2}
$$

if $\left(S E_{\log }\right)_{s v_{2}}$ is assumed to equal $\left(S E_{\log }\right)_{s v}$ and $\left(S E_{\log }\right)_{s x_{2}}$ is assumed to equal $\left(S E_{\log }\right)_{s x}$.

Each of the components of variance in equation 12A is applicable for case 1. For this study, however, only $\left(S E_{s x}\right)^{2}$ and $\left(S E_{s v}\right)^{2}$ are considered. For that reason, the magnitude of values for the standard spatial error for case 1 may be underestimated.

Estimates of the standard spatial error, $S E_{e x}$, for case 1 are given in column 18 of table 1 . The estimates are based on equation $12 \mathrm{~A}$ and on numbers from table 1 and figure 2. Values for $S E_{s x}$ were taken directly from column 17 of table 1 . For the sites along the Sacramento River, numbers representing $S E_{s v}$ for a single sample at a vertical were obtained from the curve in figure 2 that was developed from equation $5 \mathrm{~B}$. The single-sample numbers that were obtained from the curve in figure 2 were divided by $\sqrt{2}$ to give an estimate of $S E_{s v}$ for two samples at a vertical. For the site on Thomes Creek, numbers representing $S E_{s v}$ for a single sample at a vertical were obtained from a relation developed using 0.025 for $k_{f}$ and 0.13 for $k_{s}$ in equation 5. Values of $S E_{s v}$ for Cottonwood Creek were based on numbers for percentage sand taken directly from column 14 of table 1 , numbers plotted in figure 2 , and the curves in figure 2 . All numbers in percentages were changed to equivalent logarithmic units before being used in equation 12A.

Only the variance $\left(S E_{\mathrm{log}}\right)_{s x}^{2}$ in equation $12 \mathrm{~A}$ is applicable for case 2 . For the study stations, the standard error of estimate, $S E_{e x}$, for case 2 is assumed to be equal to the coefficient of variation, $(C V)_{x}$. Values of $(C V)_{x}$ for the study stations are given in column 15 of table 1 . A bias error, however, may be introduced when $(C V)_{x}$ is used to represent $S E_{e x}$.

\section{TEMPORAL ERROR}

\section{DISCUSSION OF ERROR}

Temporal error is the difference between the computed and the true mean suspended-sediment concentration for a cross section for any point in time. Basically, it is the error in values taken from a curve that represents the temporal variation in mean suspendedsediment concentration for a section. In terms of concentration in milligrams per liter, an equation for the temporal error is

$$
R_{c x p}=C_{t x p}-C_{c x p}
$$

in which

$$
\begin{gathered}
R_{c x p}=\text { difference between true and computed mean } \\
\text { concentration for a section for any point in } \\
\text { time, } \\
C_{t x p}=\begin{array}{l}
\text { true mean concentration for the section for any } \\
\text { point in time, and }
\end{array} \\
C_{c x p}=\text { computed mean concentration for the section } \\
\text { for any point in time. }
\end{gathered}
$$

The subscript $c$ denotes a parameter taken from a concentration curve, and the subscript $p$ denotes a parameter for a single point in time. The magnitude of the temporal error for data representing mean concentration for a cross section typically depends on (1) the natural variability of the suspended-sediment concentration in the vertical, across the section, and in time, (2) the sampling error and the spatial error, (3) the frequency of sampling, (4) the type and use of other available data (streamflow, temperature, and precipitation), and (5) the experience and good judgment of the 
hydrologist developing the temporal concentration curve.

The development of a temporal curve representing the mean concentration for a section may be based on single-point, single-vertical, or multivertical samples. As is discussed in the following section, the procedure used to approximate the standard temporal error is about the same regardless of the basis for the development of the temporal concentration curve.

\section{APPROACH TO SOLUTION}

The approximation of the variance of the difference between the true and the computed mean concentration at a section for any point in time, $\left(S E_{c x p}\right)^{2}$, cannot be based directly on measured or sampled values of concentrations because data are inadequate. For this study, the approximation is obtained indirectly and is based on the following equation:

$$
\left(S E_{c x p j}\right)^{2}=\left(S E_{x j}\right)^{2}+\left(S E_{c p j}\right)^{2},
$$

in which the variance $\left(S E_{x j}\right)^{2}$ represents the spatial uncertainty and the variance $\left(S E_{c p j}\right)^{2}$ represents the temporal uncertainty introduced in developing a concentration curve. The subscript $j$ denotes a parameter that is based on samples of concentration for a single point, for a single vertical, or for multiverticals. Approaches for approximating $S E_{x j}$ are described in preceding sections, and values representing $S E_{x j}$ are given in columns 17 and 18 of table 1.

Values of $\left(S E_{c p j}\right)$ can be obtained by comparing computed values of suspended-sediment concentration for a single point, a single vertical, or multiverticals with sampled values when the error in the sampled values is known. The variance of the difference between computed and sampled suspended-sediment concentration may be estimated as follows:

$$
\begin{aligned}
S E_{(s p j-s c j)} & =\left(C_{s p j}-C_{c p j}\right)^{2} \\
& =\frac{\sum\left[\left(C_{t j}+R_{c p j}\right)-\left(C_{t j}+R_{s p j}\right)\right]^{2}}{N_{2}} \\
& =\frac{\left(R_{c p j}-R_{s p j}\right)^{2}}{N_{2}},
\end{aligned}
$$

in which

$R_{c p j}=$ the difference between computed concentration, $C_{c p j}$, and true concentration, $C_{t j}$,

$R_{s p j}=$ the difference between sampled concentration, $C_{s p j}$, and true concentration, $C_{t j}$, and

$N_{2}=$ the number of values in the sample group.

The expected value is

$$
E\left(S E_{(s p j-c p j)}^{2}\right)=\sigma_{(s p j-c p j)}^{2}=\sigma^{2}{ }_{c p j}+\sigma^{2}{ }_{s p j}
$$

if the errors for the sampled group are independent from the errors in the control group. Therefore, $\sigma^{2}{ }_{c p j}=\sigma_{(s p j-c p j)}-\sigma^{2}{ }_{s p j}$ where $\sigma^{2}$ denotes a true or population variance, in contrast with $(S E)^{2}$, which is estimated on the basis of data.

Equations 16, 17, and 18 can be used to estimate the temporal standard error for suspended-sediment records that are based on concentrations for a single point or a single vertical, or on the mean of concentrations for multiverticals. Generally, the approach is the same as that used by Burkham and Dawdy (1970) to appraise the accuracy of streamflow data for an alluvial stream. Values for the right side of the equations, representing independent errors, would be different for the three procedures for determining concentrations for a section.

\section{APPLICATION OF METHOD}

\section{BASIC DATA}

Suspended-sediment records for a site on Cottonwood Creek near Olinda, Calif., and for a site on Bixler Run near Loysville, $\mathrm{Pa}$., were used to demonstrate the procedure for estimating the standard temporal error, $S E_{\text {cxp }}$. The concentration record for the Cottonwood Creek site is based on suspended-sediment samples obtained periodically at a single permanently located vertical and verification samples taken occasionally at the site. The concentration record for the Bixler Run site is based on suspended-sediment samples obtained periodically at a single point in the stream. The samples for Bixler Run were obtained by pump sampler. The periods of record (study periods) used in the analyses of standard temporal error were October 4, 1977, to March 2, 1979, for the site on Cottonwood Creek and March 12-15, 1962, for the site on Bixler Run (table 1).

At the site on Cottonwood Creek, the daily discharge ranged from 9.1 to $10,100 \mathrm{ft}^{3} / \mathrm{s}$ during the study period and the daily concentration ranged from 0 to 3,600 milligrams per liter. According to the results of particle-size analyses, the part of the suspended sediment that is sand ranged from 3 to 60 percent during the study period. Cottonwood Creek at the Olinda site drains a watershed of about $395 \mathrm{mi}^{2}$.

At the site on Bixler Run, the daily discharge ranged from 88 to $132 \mathrm{ft}^{3} / \mathrm{s}$ and the daily concentration ranged from 8 to 616 milligrams per liter during the study period. According to the results of particle-size analyses, the part of the suspended sediment that is sand was 3 percent on February 26, 1962, 5 percent on March 12, 1962, and 4 percent on March 21, 1962. Bixler Run at the Loysville site drains a watershed of about $15 \mathrm{mi}^{2}$. 
ANALYSIS OF DATA

Analyses to approximate the standard temporal error were made by steps, as follows:

1. The variance representing the difference between computed and sampled suspended-sediment concentration, $S E_{(s p j-s c j)}^{2}$, was determined.

2. The variance representing $S E_{c p j}^{2}$ was obtained by subtracting a variance representing $S E_{s p j}^{2}$, variance for sampled concentration, from the variance obtained in step 1.

3. The variance representing $\left(S E_{c x p}\right)^{2}$ was obtained by adding a variance representing $\left(S E_{x j}\right)^{2}$ to the variance $S E_{c p j}^{2}$ obtained in step 2.

4. The standard temporal error $\left(S E_{c x p j}\right)$ was obtained by taking the square root of $\left(S E_{c x p j}\right)^{2}$.

The same analytical procedure was used to determine $S E^{2}{ }_{(s p j-c p j)}$ for the data of both sites. Logarithmic units were used in the analyses. Analyses for the determination of $S E^{2}{ }_{(s p j-c p j)}$ (step 1) were made using the values of concentration for $1 / 6,1 / 4,1 / 3,1 / 2,2 / 3$, and $3 / 4$ of the total number of samples available for the development of temporal concentration. The sets of data are overlapping and, therefore, the results are not entirely independent. No corrections for lack of independence were included in the analyses. The samples were arranged in groups of six by time. From each group, one sample was selected randomly and used in the analyses to develop the temporal concentration curve. The remaining samples were retained as the control group. After the temporal concentration curve was developed, concentrations were obtained from the curve corresponding to the times of the samples in the control group. The mean square difference between the logarithms of the computed and sampled concentrations was then determined.

Similar analyses to determine $S E^{2}{ }_{(s p j-s c j)}$ and $S E_{c p j}^{2}$ were made for the studies in which $1 / 4,1 / 3,1 / 2,2 / 3$, and $3 / 4$ of the total samples were used to develop the temporal concentration curve. Because analyses were made using logarithmic units, the standard errors could be readily changed to percentages.

\section{STANDARD TEMPORAL ERROR}

The relations of the average time between samples to percent error in instantaneous concentrations for the two sites-on Cottonwood Creek and Bixler Run-are shown in figure 4. The trend lines drawn through the points and extended to minimum values illustrate the average improvement in developing temporal concentration curves with decrease of time between samples. The minimum error is assumed to be the coefficient of variation-18 percent for the Cottonwood Creek site and 4 percent for the Bixler Run site. Presumably, the minimum error could be realized only if samples were obtained continuously at the single vertical at the
Cottonwood Creek site and at the single point at the Bixler Run site.

The extrapolation of the relations shown in figure 4 makes it possible to estimate errors that would result if all samples were used to develop the temporal concentration curve. For the Cottonwood Creek site, where the average time between samples is 4.5 hours, the estimated standard temporal error is 72.5 percent. For the Bixler Run site, where the average time between samples is 1.2 hours, the estimated standard temporal error is 14 percent.

The relations of time between samples to percent error in instantaneous concentrations that are given in figure 4 suggest better accuracy for the Bixler Run record. This undoubtedly reflects the uncertainty caused by the higher percentage of sand-sized sediment in suspension at the Cottonwood Creek site.

As previously indicated, the trend line drawn through the plotted points for the Cottonwood Creek site (fig. 4) represents the average relation between the standard temporal error and time between samples. Had the data for the Cottonwood Creek site been adequate, curves could have been developed that would show the relation between the standard temporal error and time between samples for periods when the percentage sand is relatively low and for periods when the percentage sand is relatively high.

\section{SEDIMENT-DISCHARGE ERROR}

\section{DISCUSSION OF ERROR}

Sediment-discharge error is the difference between computed and true sediment discharge for a cross section for any point in time. In terms of sediment discharge in tons per second, an equation for sedimentdischarge error is

$$
R_{q x}=(Q S)_{c x}-(Q S)_{t x},
$$

in which

$R_{q x}=$ the difference between computed and true sediment discharge,

$(Q S)_{c x}=$ computed sediment discharge, and

$(Q S)_{t x}=$ true sediment discharge.

The subscript $q$ denotes a sediment-discharge parameter. As discussed in detail in a subsequent section, sediment discharge is the result obtained when the product of concentration times water discharge is multiplied by a constant. The error in data representing sediment discharge, therefore, results from uncertainties in values of instantaneous sediment concentration and in values of water discharge. Errors in instantaneous sediment concentration are described in a preceding section. 


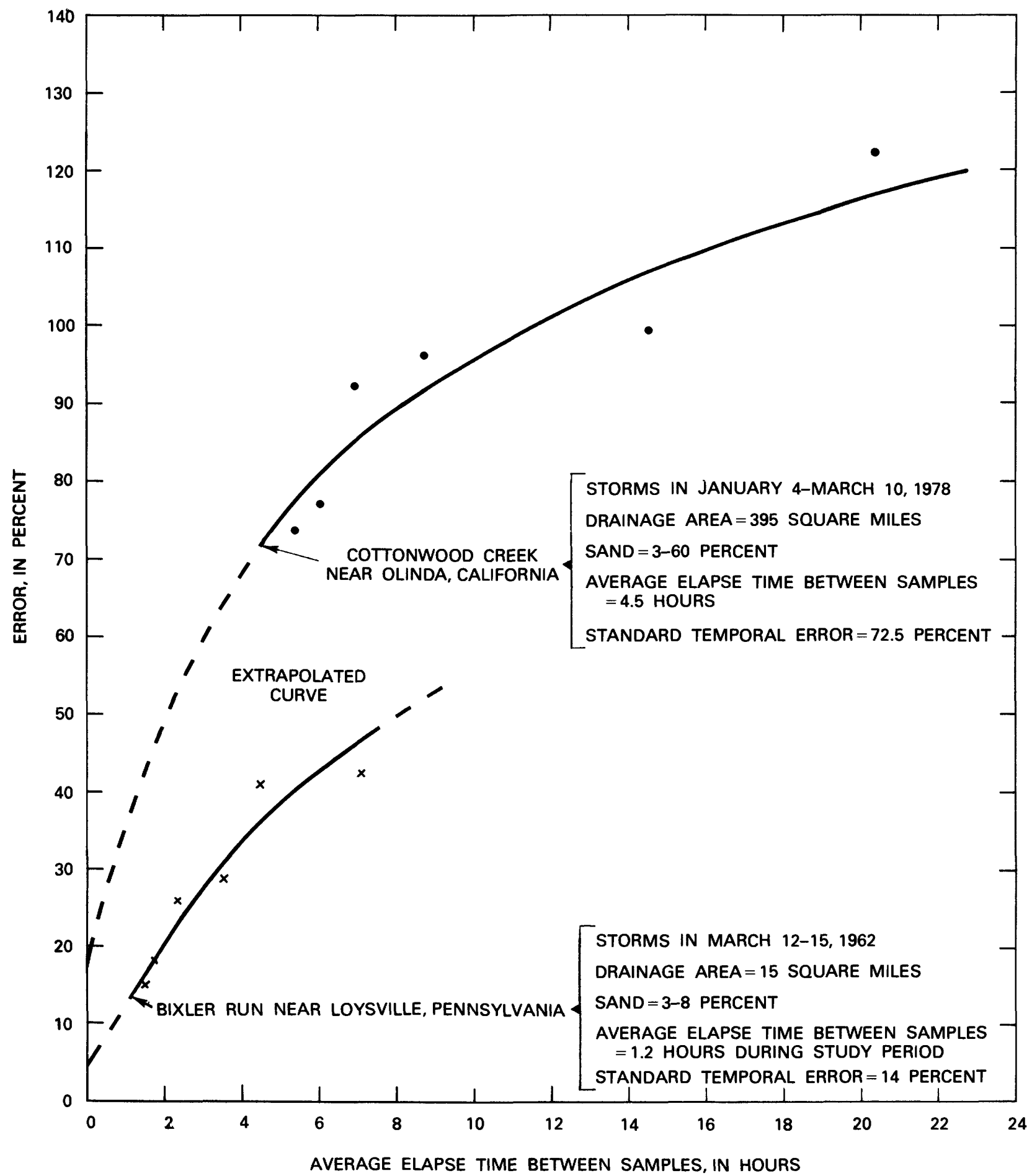

FIGURE 4.- Relation between standard temporal error in instantaneous concentration and the average elapsed time between samples for the two indicated sites. 
The magnitude of the streamflow error typically is closely related to how well the stage-discharge relation can be defined. Relatively smaller errors, however, may result from the incorrect recording of stage and time. If a stable stage-discharge relation exists at a gaging site, a rating defined by a large number of current-meter measurements-assuming the measurement errors have a mean of zero-would approach the true stage-discharge relation. Discharge computed by applying a correct stage record to the rating thus defined would have only a relatively small error. The rating conditions in most alluvial channels are not perfect or stable. Changes in the dimensions of the channel or in the hydraulic resistance to flowing water may cause large adjustments or shifts in the stagedischarge relation. The magnitude of the streamflow error for flow in a shifting stream often is closely related to the frequency of discharge measurements and to how well the "shifts" can be estimated by the hydrologist (Burkham and Dawdy, 1970).

\section{APPROACH TO SOLUTION}

The approach for approximating the standard sediment-discharge error involves the addition of variances for the temporal error and the water-discharge error. In terms of discharge in tons per second, an equation for sediment discharge for a section is

$$
Q S=k_{1}\left(C_{c x p j}\right)(Q W)
$$

in which

$$
Q S \text { = sediment discharge, in tons per second; }
$$

$k_{1}=\mathrm{a}$ coefficient that is based on the unit of measurement of water discharge and that assumes a specific weight of 2.65 for sediment; $k_{1}$ has a value of $3.12 \times 10^{-8}$ when the units of sediment discharge are in tons per second;

$C_{c x p j}=$ the mean concentration for a section, in milligrams per liter; and

$Q W=$ water discharge, in cubic feet per second.

In logarithmic units, the variance for $Q S$ can be represented as

$$
\left[\left(S E_{\mathrm{log}}\right)_{q s}^{2}\right]=\left[\left(S E_{\mathrm{log}}\right)_{c x p j}^{2}+\left(S E_{\mathrm{log}}\right)_{q w}^{2}\right]
$$

in which

$$
\begin{aligned}
\left(S E_{\mathrm{log}}\right)_{q s} & =\text { standard sediment-discharge error, } \\
\left(S E_{\log }\right)_{c x p j} & =\text { standard temporal error, and } \\
\left(S E_{\log }\right)_{q w} & =\text { standard water-discharge error. }
\end{aligned}
$$

The coefficient $k_{1}$ is assumed to be a physical constant, and, therefore, it would have no variance component.
Equation 21 can be used to estimate the standard sediment-discharge error. The variance $\left(S E_{\mathrm{log}}\right)_{c x p j}^{2}$ can be approximated using the procedure previously presented. The variance $\left(S E_{\log }\right)_{q w}^{2}$ for data for streams having movable boundaries can be determined from measured values of streamflow using the procedure outlined by Burkham and Dawdy (1970). The variance for data for streams having rigid boundaries can be approximated from measured values of streamflow and regression analysis.

\section{APPLICATION OF METHOD}

Standard sediment-discharge errors for the Cottonwood Creek and Bixler Run sites are approximated using equation 21 . The standard temporal error is assumed to be 72.5 percent for the Cottonwood Creek site and 14 percent for the Bixler Run site (column 19 of table 1). For this report, the standard streamflow error is assumed to be 10 percent for both sites. The resulting standard sediment-discharge error is 73.2 percent for the Cottonwood Creek site and 16.8 percent for the Bixler Run site.

\section{SUMMARY AND CONCLUSIONS}

Procedures that can be used to appraise the accuracy of suspended-sediment data are described in this report. Because the computation of suspended-sediment discharge at a site on a stream involves the approximation of suspended-sediment concentration in the vertical, across the stream, and in time, the procedures described herein encompass errors for three dimensions and for suspended-sediment discharge. As defined for this study, the types of errors involved are

1. Sampling error-error introduced in obtaining a value representing suspended-sediment concentration for a sample taken at a single vertical during the sampling time.

2. Spatial error-error in mean concentration that is determined from sampled concentrations at verticals in a cross section for a point in time.

3. Temporal error-error in computed values of suspended-sediment concentration for a section for any point in time.

4. Sediment-discharge error-error in computed values of suspended-sediment discharge for a section for any point in time.

The four types of error are treated separately; however, as discussed in the report, they are not mutually independent. The standard error of estimate is the statistic used to represent error. The procedures for appraising the accuracy of suspended-sediment data are illustrated using readily available data from reports and from the files of the Water Resources Division of the U.S. Goological Survey. Suspended-sediment data for 
17 gaging stations in Arizona, California, Nebraska, New Mexico, Pennsylvania, and Washington were used in the applications of the procedures.

Conclusions resulting from the study are

1. The magnitudes of the different types of error vary directly with the percentage of the sedimentwater mixture that is sand.

2. For seven sites on the Sacramento River, Calif., and its tributaries, the standard sampling error, on an average, apparently can range from 2.5 percent for periods when the percentage of the suspended sediment that is sand is relatively low to 20 percent when the percentage sand is relatively high. When the percentage sand is relatively high, the standard sampling error apparently can range from 13 to 20 percent.

3. For 16 sites in Arizona, California, Nebraska, New Mexico, and Pennsylvania, the coefficient of variation for concentration of suspended sediment across streams apparently can range from 2.5 percent for periods when the percentage sand is relatively low to 70 percent when the percentage sand is relatively high. When the percentage sand is relatively high, the coefficient of variation may range from 20 to 70 percent among the 16 sites.

4. The average standard temporal errors for a site on Cottonwood Creek near Olinda, Calif., and for a site on Bixler Run near Loysville, Pa., increase rapidly with time between samples. The average standard temporal error was determined to be 72.5 percent for the Cottonwood Creek site and 14 percent for the Bixler Run site. Concentration curves for the Cottonwood Creek site were based on single-vertical samples of the water-sediment mixture taken with a 4.5 -hour average time between samples. Concentration curves for the Bixler Run site were based on single-point samples taken with a 1.2-hour average time between samples. Cottonwood Creek at the site near Olinda drains a watershed of about $395 \mathrm{mi}^{2}$. Bixler Run at the site near Loysville drains a watershed of about $15 \mathrm{mi}^{2}$. The percentage sand in the water-sediment mixture for the Cottonwood site had a wide range-from about 3 to 60 percent - during the study period. The percentage sand for the Bixler Run site had a low rangefrom about 3 to 5 percent-during the study period.

5. The average standard sediment-discharge errors for the two sites-Cottonwood Creek near Olinda,
Calif., and Bixler Run near Loysville, $\mathrm{Pa}$--were, respectively, 73.2 and 16.8 percent. The determinations of the magnitudes of the two standard sediment-discharge errors were based on an assumed value of 10 percent for the standard waterdischarge error.

6. Much research would be required to explain the great variability in error for a given percentage sand among the study stations.

\section{REFERENCES CITED}

Burkham, D. E., and Dawdy, D. R., 1970, Error analysis of streamflow data for an alluvial stream: U.S. Geological Survey Professional Paper 655-C, 13 p.

Colby, B. R., and Hembree, C. H., 1955, Computations of total sediment discharge, Niobrara River near Cody, Nebraska: U.S. Geological Survey Water-Supply Paper 1357, 187 p.

Culbertson, J. K., Scott, C. H., and Bennett, J. P., 1972, Summary of alluvial-channel data from Rio Grande conveyance channel, New Mexico, 1965-69: U.S. Geological Survey Professional Paper 562-J, 49 p.

Dixon, W. J., and Massey, F. J., Jr., 1957, Introduction to statistical analysis: New York, McGraw-Hill, 488 p.

Guy, H. P., 1968, Quality control of adjustment coefficients used in sediment studies, in Geological Survey research, 1968: U.S. Geological Survey Professional Paper 600-B, p. B165-B168.

Guy, H. P., and Norman, V. W., 1970, Field methods for measurement of fluvial sediment: U.S. Geological Survey Techniques of Water-Resources Investigations, bk. 3, chap. C2, $59 \mathrm{p}$.

Howard, C. S., 1947, Suspended sediment in the Colorado River, 1925-41: U.S. Geological Survey Water-Supply Paper 998, $165 \mathrm{p}$.

Hubbell, D. W., 1960, Investigations of some sedimentation characteristics of sand-bed streams, progress report number 2 : U.S. Geological Survey open-file report, $78 \mathrm{p}$.

Hubbell, D. W., Jordan, P. R., Culbertson, D. M., and Hembree, C. H., 1956, Progress report number 1-Investigation of some sedimentation characteristics of a sand-bed stream: U.S. Geological Survey open-file report, $78 \mathrm{p}$.

Hubbell, D. W., and Matejka, D. Q., 1959, Investigations of sediment transportation, Middle Loup River at Dunning, Nebraska: U.S. Geological Survey Water-Supply Paper 1476, 123 p.

Porterfield, George, 1972, Computation of fluvial-sediment discharge: U.S. Geological Survey Techniques of WaterResources Investigations, bk. 3, chap. C3, 66 p.

Skinner, J. V., and Beverage, J. P., 1981, Test and design of automatic fluvial suspended-sediment sampler; Report W: U.S. Army Engineer District, St. Paul, Minnesota, 53 p.

U.S. Geological Survey, 1977, Sediment, in National handbook of recommended methods for water-data acquisition, chap. 3 , p. 3-1-3-99.

U.S. Inter-Agency Committee on Water-Resources, Subcommittee on Sedimentation, 1943, Determination of fluvial sediment discharge, Report 14 of A study of methods used in measurement and analysis of sediment loads in streams: $151 \mathrm{p}$. 